\title{
Expansion Strategies of a Mutual Help Organization $^{1}$
}

\author{
Marc A. Zimmerman ${ }^{2}$ \\ University of Michigan \\ Thomas M. Reischl \\ Michigan State University
}

Edward Seidman

New York University

Julian Rappaport

University of Illinois at Urbana-Champaign

Paul A. Toro

State University of New York at Buffalo

\section{Deborah A. Salem}

University of Michigan

Described a study of the expansion strategies of a successful self- and mutual help organization for persons with mental illness. Resource mobilization and behavior-setting theories were used as conceptual frameworks to guide the investigation. Collaborative methods and a grounded theory approach were used.

${ }^{1}$ This research was supported by grant \#MH37390 from the National Institute of Mental Health to Julian Rappaport and Edward Seidman. We thank the members of GROW, its staff, and especially Con Keogh for taking the time and effort to provide us with detailed information about their organization and for allowing us access to their work settings and private meetings.

${ }^{2}$ All correspondence should be sent to Marc A. Zimmerman, Department of Health Behavior and Health Education, School of Public Health, University of Michigan, Ann Arbor, Michigan 48109-2029. 
Archives, reports of contacts outside of the organization, and naturalistic observations were data sources. Of particular interest are the processes used by the organization to mobilize internal and external resources and to start new mutual help groups. Results suggest that the organization mobilizes resources from a variety of sources, displays flexibility in securing resources and defining organizational roles, and creates underpopulated settings to encourage individual involvement. The strategies appear to avoid overtaxing resource pools, reduce role ambiguity, and encourage pluralistic participation. Discussion includes several potential explanations for the successful growth of the organization.

The current trend of decreased Federal government funding for human service programs coupled with the need for community services for persons with a history of serious problems in living underscores the need for locally initiated efforts to address human problems (Salem, Seidman, \& Rappaport, 1988). Self- and mutual help organizations represent one way to address both of these issues. ${ }^{3}$ The Surgeon General's Workshop on SelfHelp and Public Health has helped to make grass-roots efforts a legitimate part of the health and human service delivery system (U.S. Department of Health and Human Services, 1988). Mutual help organizations augment mental health services by providing opportunities for members to develop personal resources and a psychological sense of community (Gartner \& Riessman, 1984; Riessman, 1985). They may also require less funding than professional services because they rely on volunteer helping and localized funding for successful development.

Despite the proliferation of mutual help groups and their potential benefits (Levine, 1988; Jacobs \& Goodman, 1989; Maton, Leventhal, Madara, \& Julien, 1988), there have been few opportunities for researchers to study the growth and development of mutual help organizations. Much of the research on mutual help has focused on individual outcomes (Bailey, 1965; Barrett, 1978; Galanter, 1988; Hinrichsen, Revenson, \& Shinn, 1985; Raiff, 1984; Spiegel, Bloom, \& Yalom, 1981), or group process (Biegel \& Yamatani, 1987; Levy, 1979; Luke, Rappaport, \& Seidman, 1991; Roberts, 1989; Wollert, 1986; Wollert, Levy, \& Knight, 1982). A notable exception is Kurtz's (1979) historical analysis of the development of Alcoholics Anonymous. The research reported here describes the successful growth of a mutual help organization for persons with mental illness. It departs

\footnotetext{
${ }^{3}$ Self- and mutual help organizations refer to voluntary organizations operated by lay people who share a common experience and assist each other in coping with the experience. Maton et al. (1988) provide a more in-depth definition. In this paper we use the term "mutual help" to include both self- and mutual help organizations, although others have made a distinction between these (Levine, 1988).
} 
from past efforts in that we were able to observe the organization's growth from shortly after its inception in Illinois.

This research is intended to describe the processes by which the organization developed. The study emerged from our initial involvement with the organization soon after it appeared in Illinois. We anticipated its potential to have an influential and lasting effect on mental health care in the State and perhaps beyond. As a result, this study was commenced to document how the organization might develop from a small local one to a large and geographically dispersed social movement organization. The research was guided by an integrated conceptual framework of resource mobilization theory (McCarthy \& Zald, 1977) and the ecology of settings (Barker, 1960; Wicker, 1987). We utilized grounded theory methods (Glaser \& Strauss, 1967) to study the organization because we were interested in discovering techniques and describing processes used by the mutual help organization to expand and disseminate its program.

\section{CONCEPTUAL FRAMEWORK}

Resource mobilization theory (Ferree \& Miller, 1985; Jenkins, 1983; McCarthy \& Zald, 1977) provides a useful framework for our study because it was developed from an interest in understanding social movement organizations and focuses on resource identification, acquisition, and management. Borkman (1990) suggested that considering self- and mutual help organizations as social movements helps us understand their influence in the mental health service system. She pointed out that several self- and mutual help organizations meet the criteria of a social movement organization, regardless of their size or power, because they promote ideological stands, press for civil rights, and attempt to change or influence the health and mental health service systems.

Resource mobilization theory suggests that social movement organizations' successful growth partly depends on the effectiveness of their strategies for mobilizing needed resources-funding, facilities, and members (McCarthy \& Zald, 1977). Resource mobilization includes identifying community supporters, finding a niche in a competitive social movement market, and examining internal organizational structures that inhibit or enhance resource development. Others have also identified resource issues as a critical aspect of organizational development (Bartunek \& BettersReed, 1987; Kegan, 1981). Our investigation emphasized the description of resources needed for organizational growth; processes used to identify, secure, and maintain these resources; and organizational structures and qualities that impeded or facilitated resource development. 
Barker's manning theory was also used to guide our inquiry (Barker, 1960; Barker \& Gump, 1964; Wicker, 1987). ${ }^{4}$ Barker identified underpopulated and overpopulated behavioral settings. Underpopulated settings have less than the optimal number of participants or more social roles than persons available to occupy each role. Overpopulated settings have more than the optimal number of participants or fewer social roles than persons available to occupy each role. Barker found that the population level of a setting had a predictable impact on the behavior and experience of individuals within a setting, including increased participation in more responsible, difficult, and varied roles and enhanced feelings of importance.

Barker's concepts helped us formulate a perspective that integrated the ecology of behavior settings with the mobilization of human resources. The process by which new groups are developed may be critical for the survival of mutual help organizations. Organizations that create settings before the optimal number of members are available to fill the roles necessary for group maintenance may expand quickly, but they may also be more likely to fail because they have expanded beyond their means. We have likened this tactic to Johnny Appleseed's strategy of planting apple trees in the wilderness in anticipation of settlers to come (Zimmerman et al., 1985). Similarly, a mutual help organization may expand by starting groups in anticipation of participants to join.

Alternately, strategies that extend new groups only when all the roles in existing groups are filled (i.e., overpopulated groups) may result in fewer group failures but slower rates of expansion and more limited dissemination. A cell division analogy - cells splitting in two once a critical level of growth is achieved-characterizes this approach. One goal of this study is to examine which approach best describes the organization's expansion strategy.

\section{METHODOLOGICAL FRAMEWORK}

Our research strategy was similar to the approach of qualitative and ethnographic researchers (see Emerson, 1983; Van Maanen, 1983) with discovery as the goal. In this regard we have taken seriously the recommendation of the Surgeon General's report (U.S. DHHS, 1988) that researchers use methods appropriate to the study of self- and mutual help rather than

\footnotetext{
${ }^{4}$ The term "manning theory" - originally coined by Barker-is used once in keeping with historical usage to make it easier for the reader to locate the theory in the literature. The gender neutral term "underpopulated" (Perkins, Burns, Perry, \& Nielsen, 1988) is used to replace "undermanned" in the paper.
} 
to insist solely on traditional experimental methods or hypothesis-testing research.

We chose to design the study using descriptive case study methods for two reasons. First, we wanted to remain flexible with our data collection strategies so we could maximize our opportunities for learning how the organization developed over time. Thus, we were able to modify our research plan as the study progressed to address questions that we did not anticipate and to further investigate activities that appeared particularly interesting. Second, we wanted to conduct research consistent with our collaborative approach (Lincoln \& Guba, 1986; Rappaport, 1990) and take advantage of the fact that over time we would have access to a variety of unanticipated settings in which the organization would conduct its activities. Kelly (1988) suggested that community research should take advantage of close ties with research participants and nurture such relationships to obtain a more in-depth and ecological understanding of the participants and their settings.

The goal of this study is not theory verification, rather our approach corresponds to grounded theory methodology (Glaser \& Strauss, 1967). Grounded theory methods stress discovery and theory development, and encourage data collection and analysis to occur simultaneously so the research can be adapted to examine emerging themes (see Charmaz, 1983). Grounded theory also emphasizes studying process as well as outcome (Charmaz, 1983). Additionally, our methods included investigative reporting techniques (Levine, 1980). In this method, the research team meets regularly to discuss the progress of a line of inquiry much like newspaper editors discuss the progress of a story. We used data collected to help identify more questions to explore and to identify new sources of information to verify findings.

In some respects, our methodology is also consistent with Wicker's (1989) notions of "substantive theorizing," emphasizing long-term research commitments and the ecologically oriented study of processes in their social and temporal context. The nature of research such as this, however, may raise questions about the validity of the observational data reported. Although validity of observational data does not have the same meaning as that used in traditional psychometric theory (see, for example, Lincoln \& Guba, 1986), we took several steps to consensually validate the information collected, including cross-checking data with the research team and organizational members. A more complete description of the methods used to increase our confidence in the observational data is described below.

In sum, the focus of this study is on the organization's attempt to disseminate its program throughout the State of Illinois. We concentrated on resource mobilization, creation of groups, and role delineation in order 
to describe its development. A primary objective of this paper is to examine self- and mutual help at an organizational level of analysis, by describing the processes used by the organization to expand. The research augments the organizational development literature by describing the growth of a notfor-profit community-based voluntary organization. Our efforts use a grounded theory approach to take advantage of our unique opportunity of being intimately involved with the organization at the earliest stages of its development in Illinois.

\section{THE RESEARCH SETTING}

The research was conducted in a mutual help organization for persons with mental illness called GROW. ${ }^{5}$ GROW is a highly developed organization with a long history and a well-established organizational structure. GROW began in 1957 in Sydney, Australia, when a handful of formerly hospitalized psychiatric patients attending Alcoholics Anonymous (AA) established their own support group. The founding members met weekly using methods and concepts similar to AA. Like AA, GROW continues to refer to spiritual beliefs and powers greater than oneself in their mutual help groups. GROW has an international headquarters located in Australia to administer over 500 GROW groups that meet in countries around the world, including Australia, New Zealand, Ireland, Great Britain, Canada, and the United States. GROW has an explicit goal of expansion so they can reach as many people as possible. GROW came to Illinois in 1978. In 1981, we began a collaborative relationship with the organization.

A GROW group typically consists of 3 to 19 members who meet for 2 hours each week. During the course of our investigation the average number of members in a group was 7.84. The groups are open to anyone, but individuals with a history of mental distress, mental illness, or psychiatric hospitalization are targeted. Each group has three formal leadership roles: (a) Organizer, (b) Recorder, and (c) Group Leader. The Organizer and Recorder are volunteers elected by group members. The Organizer's role is to keep the group on task and consistent with GROW's principles; to arrange for the meeting place; and to remind and encourage members to attend the meetings. The Recorder helps the Organizer and, at the end of the meeting, records members' appraisal of the quality of the meeting. The Organizer and Recorder also purchase refreshments for

\footnotetext{
${ }^{5}$ The data reported here were collected as part of a larger longitudinal study of a mutual help organization for the mentally ill called GROW. The project involved exploration of individual change, small group processes, and organizational development (see Rappaport et al., 1985, for a more detailed overview).
} 
a postmeeting social hour. Each week the Organizer selects one member to serve as leader for that meeting. The Leader (also a volunteer) is usually a regular group member who has demonstrated a working knowledge and commitment to the GROW program. Several informal roles which are filled by many members also exist in each group including contacting people between meetings, organizing informal social gatherings, or recruiting new members.

GROW has a small paid staff of Fieldworkers whose primary role is to start new groups and visit existing groups to assure that they operate according to GROW principles. Fieldworkers are typically members who have progressed through several leadership positions (e.g., Recorder, Organizer). At its largest stage of development during this study, 13 Fieldworkers worked for GROW in Illinois. This constituted approximately $6 \%$ of the leadership positions in the Illinois organization $(N=200)$. All other leadership positions (94\%) were filled by volunteers.

Fieldworkers have several specific responsibilities including training members for leadership positions, public relations, and community education. The Fieldworkers may also run the mutual help groups until members are ready to fill the roles of Organizer and Recorder. To start a new group, Fieldworkers must secure a setting for weekly meetings; recruit members; and facilitate the selection and training of a group Organizer who will assume the responsibility for running the group according to the standardized group method. Fieldworkers' public relations efforts include presentations and discussions with hospital administrators, mental health professionals, clergy, social service providers, and interested lay persons.

GROW also operates drop-in centers which serve as headquarters for the organization in specified geographical areas. GROW centers serve as an office for the Fieldworkers, and may be the sites for weekly meetings and monthly training sessions. When fully developed, a GROW area includes a center and 10-12 groups with at least one orientation group in a nearby inpatient facility. The orientation group is an abbreviated group designed to familiarize hospitalized patients with GROW.

\section{METHOD}

Three sources of data were used to describe the expansion of GROW: (a) archival data, (b) logs completed by Fieldworkers about their expansion related contacts, and (c) investigative reporting (Levine, 1980) and naturalistic observations. 


\section{Archival Data}

GROW maintained some documentation of when groups started and when they closed. This documentation, pieced together by the research team, allowed for a month-to-month accounting of GROW's cumulative growth of groups in the various geographic regions. GROW's financial records noted the dates of new Fieldworker hirings, another indicator of organizational expansion. A similar approach was used by Lindgren (1987) to study the development of a citizen advocacy group.

\section{Fieldworker Contact Logs}

From January 1984 to January 1986, Fieldworkers were asked to keep a $\log$ of all of the persons they had been in contact with for the purpose of promoting GROW's program. Fieldworkers recorded the contact person's name and community role (job), the geographical location, and whether the purpose of the contact was to gain access to any of the following resources: potential members, meeting space, financial support, or forums for providing information about the GROW program. This procedure generated information about 571 contacts with persons outside the organization. Fieldworkers completed the logs for $90 \%$ of the study months. ${ }^{6}$ All individuals who worked as Fieldworkers for any time during the study period completed logs for at least 1 month $(N=16)$.

Seven Fieldworkers were former group organizers from the Illinois groups; 6 were brought in from the Australian organization; and 3 were hired without prior GROW experience, but had previous training or experience in mental health service delivery. All but one of the Fieldworkers were women. Their mean age was 44.1 years $(S D=7.4)$.

Two researchers categorized the contact person's community role by consensus procedure. The role categories were further reduced to four broad community roles: (a) Community and Public Officials, (b) Mental Health Professionals, (c) the General Public, and (d) the Clergy. Reliability estimates were not calculated because each role category was discussed and decided upon by mutual agreement rather than blind review.

${ }^{6}$ The response rate was calculated by summing the total number of months worked by Fieldworkers during the 2-year study period and dividing it by the number of months they recorded contacts. Not all Fieldworkers were employed for the entire study period. A total of 148 of the 163 possible months were recorded. 


\section{Investigative Reporting and Naturalistic Observations}

From January 1984 to January 1986, GROW allowed investigators to observe most organizational events and interactions with outside contacts. We attended meetings, public presentations, and leadership training sessions. We also observed GROW's staff meetings where Fieldworkers discussed tactics for starting new groups and selecting group and organizational leaders. ${ }^{7}$

The occasions to observe GROW staff in action were chosen to represent a variety of organizational events. We selected events that involved some kind of resource mobilization effort such as community forums for recruiting members, presentations to hospital staff for encouraging referrals, efforts to obtain financial support from government officials, and internal organizational meetings (e.g., budget and program committee meetings). We were aided in our selection process by attending regular GROW staff meetings where the next month's activities were discussed. We also talked with GROW staff to learn about the meetings they considered most important.

In addition to this intensive observation of GROW's expansion strategies, we had opportunities to question GROW's leaders about their activities and to interview persons who had been in contact with GROW's leaders. The number of interviews were not recorded as they were informal and were conducted on an ad hoc basis to clarify information, obtain people's perceptions of an event, or elaborate upon existing information.

Several methods were used to improve the validity of the observational data. First, the research staff involved in this descriptive study presented impressions and observations at the regular research team meetings for the entire project. The larger research team included several individuals with various roles in the research (e.g., observing mutual help meetings, interviewing members about personal issues) that were not directly involved with this part of the project. These other research staff members were able to validate or clarify information based on their conversations with GROW members. Second, similar discussions were held with GROW staff. They also read earlier drafts of this manuscript to check for accuracy in our description of their activities and to comment on our impressions. Finally, we used triangulating methods to insure consistency in the data. The data reported are from a variety of sources (e.g., archives, Fieldworker reports, observations) and they converged on the themes discussed below.

\footnotetext{
${ }^{7}$ The only meetings GROW asked the research team not to attend were those with Bishops and other high-ranking Catholic Church officials. GROW's Program Coordinator, a Catholic priest, felt that our presence at such meetings might compromise his natural relationship with his colleagues.
} 


\section{RESULTS}

\section{Rate of Organization Expansion}

The number of groups maintained by GROW increased almost tenfold during its first 7 years in Illinois (1978-1985), however, most of the increase occurred in years 6 and 7 (1984-1985). Archival records indicate that GROW's expansion was comparatively slow and geographically limited for its first 5 years in Illinois. From October 1978 to September 1983, GROW established 29 new groups. During this time 15 groups were closed because they had too few members, but 5 of these groups were reopened at some later date. The stacked area chart in Figure 1 illustrates the dramatic increase in the number of groups and geographical dispersion from late 1983 until the end of 1985. Apparently, successful expansion required both starting new groups and effective maintenance of groups over time.

The line tracing the top of the chart in Figure 1 represents the cumulative growth of groups statewide. The chart also indicates how the expansion in each of four regions, represented by the different shades in the graph, contributed to the total number of groups. In the early years of GROW (1979-1980) most of the groups were located in Central Illinois with very few groups (only 2) located in the Chicago region. No other region in Illinois had a GROW group. By March 1980, the Chicago groups

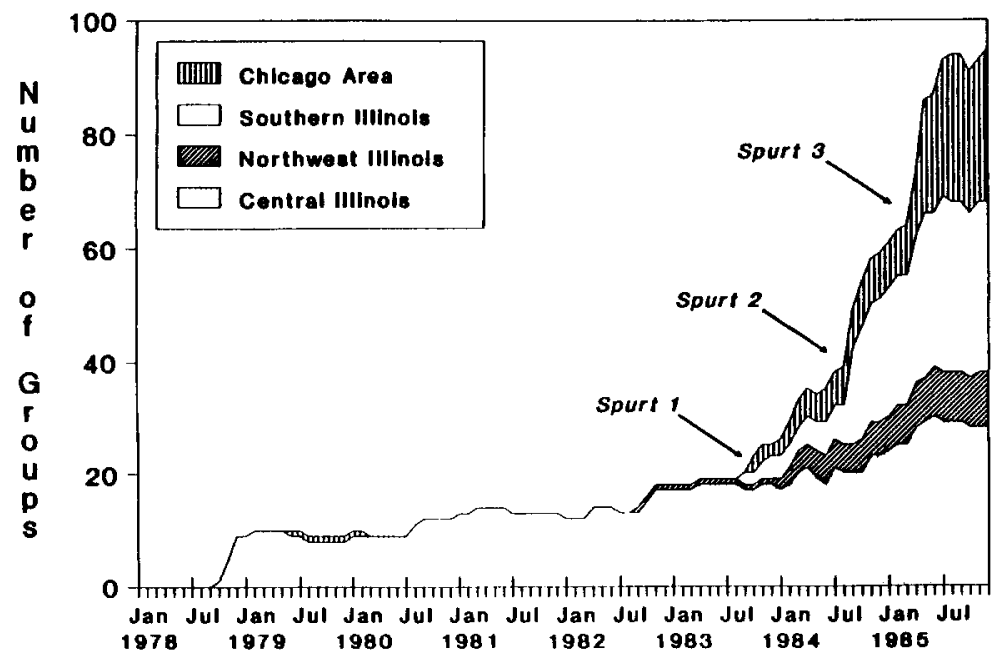

Fig. 1. Stacked area chart of cumulative growth of GROW groups in Illinois. 
were closed and until late 1982, GROW operated groups only in the Central Illinois region. By the end of 1984, GROW tripled its number of groups and was represented in all four regions of the State. The expansion continued through 1985 with most of the development occurring in Southern Illinois and the Chicago area.

Figure 1 also illustrates that most of the expansion occurred in three distinct growth spurts: Spurt 1 started slowly in September 1983, and, after a slow holiday season, the spurt finished in March 1984 (a net increase of 17 groups); Spurt 2 began in July 1984, and curtailed in November 1984 (a net increase of 23 groups); a third surge began in April 1985 and was over in July 1985 (a net increase of 33 groups). Most of the formal investigation procedures for this study began after the first growth spurt, necessitating the use of retrospective reports to account for this initial expansion.

Combining evidence from GROW's records, discussions with GROW staff when information was incomplete, and our own record keeping after September 1983, we noted that GROW started 123 groups from October 1978 to January 1986 . Thirty-three of these groups (27\%) were closed permanently or temporarily during this period. Five of the temporarily closed groups were reopened. The three growth spurts were characterized by different organizational activities and varying environmental contexts

\section{Spurt 1: Organizational Restructuring and Role Delineation}

The first growth spurt began in September 1983, but the groundwork for the expansion began a year earlier when GROW experienced a great deal of organizational strain. Up to 1983, GROW's development in Illinois was financially supported largely by a single private philanthropist who had agreed to fund GROW's start-up period in Illinois. Initial group development was directed by visiting Australian Fieldworkers and one of GROW's cofounders. They came to Illinois through an invitation by a University of Illinois psychology professor (Hobart Mowrer) to establish the first groups and train new leaders. When the start-up funds were depleted, the Australians returned home for the 1981-1982 Winter, placing the responsibility for organizational development in the hands of two Fieldworkers from the Illinois organization and a dedicated cadre of volunteers. Most of the leaders lived in Champaign-Urbana, but drove to group meetings that were held in a 90-mile radius of the cities.

This arrangement proved very difficult for the Illinois organization. Neither Fieldworker was skilled at fund-raising and the volunteers were already donating most of their free time leading or supporting groups in nearby cities. By the end of the winter, the Fieldworkers were working 
without salaries and the volunteers expressed feeling overburdened with both the group leadership and fund-raising responsibilities. Fieldworkers were unable to visit other communities and initiate new groups because of diminishing funds and they were having difficulty maintaining existing groups.

Upon hearing about the organizational difficulties in Illinois, GROW's cofounder returned to Illinois in the spring to become Program Coordinator of the Illinois organization. This role included responsibility for planning, personnel issues, coordinating activities, and fund-raising. The Program Coordinator proposed that the organization divide its human resources by creating two organizational structures with clearly delineated functions: a management team responsible for fund-raising efforts and a program team responsible for starting and supporting new groups. The Program Coordinator directed the management team while, the Fieldworkers directed the program team. In the spring of 1983 , the Program Coordinator and members of the management team began to contact potential funding sources, with most of their efforts focused on the Illinois Department of Mental Health and local County Mental Health Boards. These meetings were held to promote GROW's program and to discuss proposals for securing operational funding.

In June 1983, the Program Coordinator wrote a 3-year development plan which outlined GROW's plans for establishing and maintaining groups in all four regions of Illinois represented in Figure 1. According to the plan, funding for each regions' operations would be obtained from the State mental health budget (50\%); local government agencies $(25 \%)$; and "creative voluntary community funding" from sources such as foundations, corporations, and individual contributors (25\%). GROW used the money to pay Fieldworker salaries and travel expenses, operate GROW Centers, pay secretarial staff, and cover other office expenses (e.g., xeroxing, postage, telephone). The money was not used to actually run the mutual help groups.

The Project Coordinator convinced one of the most effective Australian Fieldworkers to spend the winter of 1982-1983 in Illinois to help him implement the first phase of the 3-year plan. The plan called for efforts to expand into three new areas of the State. Together they obtained funding to start new groups from the State Department of Mental Health Regional Director in Chicago, a Catholic Bishop in the Northwest Region, and a local County Mental Health Board in the Southern Region. By Spring 1984, there were six new groups in Chicago, three new groups in Northwest Illinois, and five new groups in the Southern Region. Five new groups were also started in Central Illinois where GROW was already established. Three 
groups in the Central region were closed during this period due to dwindling membership.

\section{Spurt 2: Cooperation with the Mental Health Service System}

Of the 22 groups added during this spurt, 15 were in rural communities of Southern Illinois. In Spring of 1984, the State Mental Health Regional Director for Southern Illinois, who had observed GROW's recent development, offered GROW $\$ 150,000$ to establish groups in this predominantly rural area. Funds were budgeted for hiring more Fieldworkers, opening and operating GROW centers, and other administrative costs.

A telephone interview with the State Mental Health Regional Director revealed that he felt GROW groups represented a relatively inexpensive way for the State to provide community support services for mental health clients. He pointed out that the State Department of Mental Health had been exploring new service options since the Governor outlined a policy to close State inpatient facilities. GROW developed an agreement with the Regional Director to hire Fieldworkers, open GROW centers, and start 26 new groups during the initial year of funding in the Southern Region. This initiative with the State, however, presented several challenges to GROW's expansion abilities and their concerns about program fidelity.

Up to this point, GROW had operated on small budgets and outside the regulations of a government body. Accepting the State's offer meant that GROW would need to keep careful records of the number of service hours they provided for clients. The State's budgeting formulas and evaluation criteria, however, were based on counting the number of service hours-individual, group, or vocational therapy-provided by professional staff to "chronically mentally ill" clients. Using this formula, GROW would only be allowed to count the time paid GROW staff (i.e., Fieldworkers) spent at a mutual help meeting and would have to identify members as chronically mentally ill individuals.

GROW adamantly opposed using the State's formula and definitions. They pointed out that the philosophy of mutual help did not fit into this professionally based funding method. Mutual help, they argued, is not a service that is provided by one individual to another, rather it is a shared experience of both receiving and providing help. GROW's leaders also expressed strong misgivings about labeling fellow members as chronically mentally ill, even if only for funding purposes. They pointed out that these labels were contrary to their objectives of integrating members back into the community. After lengthy negotiations with State officials, GROW convinced them to adopt a method of recording service hours that would count 
the number of hours members attended mutual help meetings, rather than the number of hours Fieldworkers attended meetings. They were also allowed to substitute the term "recovering GROWer" in place of chronically mentally ill. This was a significant victory for GROW because traditional accounting methods would have underrepresented the number of service hours actually provided by GROW, resulting in poor service evaluations and ultimately a reduction in State funding from the Region.

Another major challenge of the Southern Illinois expansion was facilitating the start-up of a large number of groups in rural communities. This posed several difficulties for GROW: They could not draw on existing groups to fill leadership positions, resources in rural areas were more scarce, and geographic isolation made it more difficult for Fieldworkers to support groups and facilitate leadership development. Before this rapid expansion occurred, GROW's Fieldworkers typically had more time to identify and train members of existing groups to become group Organizers or Recorders. The development of groups in rural Southern Illinois required a different strategy, because a large number of new groups would need to be established before the necessary group roles could be filled by competent members (i.e., the groups would be underpopulated).

Recognizing that they would have to start groups before leaders could be developed among the membership, GROW negotiated an agreement with the State to involve mental health professional staff as temporary group organizers (Sponsors). This strategy was employed years earlier in New Zealand, but GROW had experienced some difficulty with the professionals ignoring mutual help values. As a result, GROW avoided professional involvement except in isolated cases ever since. Nevertheless, they used this strategy again out of necessity, but only after an explicit linkage agreement was developed with the State.

The linkage agreement outlined the role of the professionals (i.e., Sponsors), indicated they would be replaced by an indigenous leader within 6 months, and required a training period for the professionals. The Southern Illinois Regional Director agreed to the plan and notified State-funded agencies in the region that they could provide paid release time to staff interested in working with GROW. GROW assigned an experienced Fieldworker to assume primary responsibility for training mental health workers as temporary group Organizers. Of the 15 new groups in Southern Illinois, 9 were started with mental health workers serving as Sponsors.

The professional involvement did have some potentially negative effects. In some cases, Sponsors remained beyond the 6-month limit because the necessary indigenous leadership did not develop. Other Sponsors left their positions or were promoted requiring GROW to accept replacements before they received adequate GROW training. Nevertheless, GROW 
monitored these groups with frequent Fieldworker visits and eventually trained new Sponsors and indigenous leaders.

\section{Spurt 3: Extending the Mobilization Model}

The successful venture in Southern Illinois encouraged GROW to approach other State Regional Directors for financial and policy support to start new groups in their areas. Based on the Southern Illinois experience, GROW developed a model for expansion that included presentations to human service agency staff in meetings sponsored by the State Mental Health Regional Directors. One-day workshops (described below) were developed to generate interest among mental health professionals, clergy, and community residents for starting new groups. The new expansion plan included professionals as group sponsors for some groups, funding for opening GROW centers, and a workshop for obtaining community support. GROW's efforts in these regions were aided by the support and recommendations of the Southern Illinois Regional Department of Mental Health administration, and the timing of the statewide mandate to establish community programs for deinstitutionalized patients. As a result, GROW established new groups in the Chicago area and in Northwest Illinois. ${ }^{8}$

Although these spurts reflect different organizational activities and environmental contexts they have in common a flexible approach to resource mobilization that included creation of underpopulated settings. The next section describes GROW's resource mobilization and group development strategies.

\section{Organizational Expansion Strategies}

After the first spurt began, we started our intensive naturalistic investigation of GROW's expansion strategies. We were especially interested in how the organization's leaders initiated new groups and how they mobilized external and internal resources. Members and indigenous leaders represent GROW's primary internal resources for operating and maintaining groups. External resources-sympathetic professionals, philanthropists, media organizations - facilitate the development of groups through membership recruitment, funding opportunities, and publicity.

${ }^{8}$ In 1990, GROW received a grant from the Robert Wood Johnson Foundation to facilitate GROW's expansion into other States. To date, they have started 7 groups in three Eastern States: New Jersey (1), Delaware (5), and Rhode Island (1). Each of these States is supporting a Fieldworker. 


\section{Strategies for Starting New Groups}

The minimal resources needed to start a group are a meeting site, a group Organizer, at least two other members (GROW's bylaws state that three persons are necessary for a meeting), and copies of key GROW publications (including the standard meeting agenda). GROW meetings are held in a variety of places including churches, community agencies, and libraries. Members are recruited from a variety of sources including inpatient and outpatient human service programs; public forums and the local media; and personal contacts of fellow members.

At monthly staff meetings, GROW's Fieldworkers discussed plans, problems, and progress in their attempts to mobilize resources to form new groups. The Fieldworkers spoke of two general processes of group formation: (a) encouraging members of a growing group (e.g., over 15 members) to form a "splinter" group and (b) starting a new group "from scratch." The splitting of an existing group into two groups is similar to cell division. In this strategy, a new group is developed as existing groups become overpopulated. This strategy is characterized by a localized and concentrated effort. Alternatively, the Johnny Appleseed approach describes the tactic of creating new groups in locations where they did not already exist (i.e., from scratch). Using this strategy, underpopulated settings are created before the necessary membership is identified.

The archival records and informal interviews with Fieldworkers indicate that nearly all the new groups started before they had sufficient membership to operate a group. From April 1983 through January 1986, GROW established 96 new groups, most of which were started with new members at new sites in new communities. Only $8(8 \%)$ were created by splitting an existing group (i.e., cell division). This strategy of starting groups from scratch had a relatively high risk for failure. Of the 96 new groups, $19(20 \%)$ were eventually temporarily or permanently closed because there were too few members. Two of the recessed groups were reopened.

Fieldworkers started groups in a variety of unplanned and opportunistic ways. They used creative and resourceful tactics to start new groups. The three strategies described below characterize GROW's spontaneous and flexible tactics.

Networking Strategies. Through investigative reporting and observations we noted that members' social networks were used for starting groups in new communities. In one case, a member of an existing group who commuted 30 miles to attend meetings reported that she had neighbors interested in attending meetings, but they were unwilling to travel 30 miles. The Fieldworker subsequently met with the interested individuals and decided that a new group was warranted. The link pin member became the group's 
Organizer and helped the Fieldworker secure meeting space and publicize the new group. Utilization of members' social networks has played a part in the development of 10 of the 53 new groups (19\%) during the 2-year period that we kept close records on group development (April 1983 to April 1985). Networks among mental health workers and State mental health administrators also helped GROW establish orientation groups in three institutions.

Community Education Events. GROW hosted several intensive 1-day workshops in various communities to attract publicity and obtain the cooperation of human service professionals. GROW staff invited local mental health professionals, clergy, church social service workers, and community residents to attend the workshops. Fieldworkers and members presented the GROW philosophy and program, and described the resources needed to start a group. The workshops also included a discussion of the role of agency staff as Sponsors and referral agents. In some workshops they even held a public GROW meeting to show the audience how a group operates. Several groups were started from the interest generated from these workshops, but the exact number is difficult to determine because the strategy was combined with other tactics (e.g., advertising, contacting hospital personnel).

Unplanned Events. Fieldworkers often turned unplanned events into opportunities to start a new group. For example, a Fieldworker was contacted by a local newspaper reporter interested in writing a story about GROW. The Fieldworker decided to take advantage of the free publicity and told the reporter that a new group was starting, even though this group was not previously planned. The Fieldworker recruited two members from another group to attend the first meeting of the new group to insure that a meeting would take place. The published story announced a new group was starting the following week. Ten new individuals attended the first meeting and provided the membership base for an ongoing group.

Career changes among GROW's supporters provided other unplanned opportunities to expand into new areas. When agency supporters in service and administrative positions shifted locations as a result of promotions or job changes, GROW would approach them again to start groups in their new communities. GROW also targeted communities where a psychiatric hospital was closing or releasing patients as a result of deinstitutionalization.

\section{Strategies for Mobilizing External Resources}

The start-up of most of the groups required gaining access to resources outside of the organization. The primary tactic for mobilizing ex- 
Table I. Number of GROW Fieldworker Contacts with Persons in Various Community Roles

\begin{tabular}{lcc}
\hline \multicolumn{1}{c}{ Role category } & $\begin{array}{c}\text { No. of contacts } \\
(N=545)\end{array}$ & $\begin{array}{c}\text { \% of total } \\
\text { contacts }\end{array}$ \\
\hline Community and public officials & & \\
Agency administrators & 152 & 28 \\
Agency staff & 41 & 8 \\
Community organization leaders & 15 & 3 \\
Appointed public officials & 11 & 2 \\
Elected public officials & 2 & - \\
Law enforcement personnel & 1 & - \\
Mental health professionals & & \\
Social workers/counselors & 108 & 20 \\
Psychiatrists/physicians & 16 & 3 \\
Nurses & 11 & 2 \\
Psychologists & 6 & 1 \\
General public & & \\
Private citizens & 60 & 11 \\
Media reporters/cditors & 39 & 7 \\
Business managers & 25 & 5 \\
Educators/students & 14 & 3 \\
Clergy & 44 & 8 \\
\hline
\end{tabular}

ternal resources was to contact community persons who could have access to resources needed to start groups. Through community contacts, Fieldworkers located resources and developed plans for starting new groups.

Community Contacts. The logs completed by Fieldworkers help delineate who they contacted and for what resources. Table I notes that Fieldworkers were in contact with persons occupying a wide variety of community roles. Community and Public Officials were the group most often contacted by Fieldworkers and most of these contacts were with agency administrators. Mental health professionals (especially social workers and counselors) were also frequently contacted. The Fieldworkers were in contact with members of the general public and the clergy to a considerable but lesser extent.

The purpose of the contacts varied across the different community role categories, however, most contacts involved publicizing GROW and recruiting members (TABLE II). Fewer contacts were for the purpose of securing meeting space and for requesting financial support. The significant chi-square tests suggest that (a) the contacts with the general public were primarily for providing information about GROW, (b) community and public officials were the least likely sources of member referrals, (c) Fieldworkers tended to limit their search for meeting space to clergy and com- 
Table II. Resources Mobilized from Persons in Various Community Roles

\begin{tabular}{|c|c|c|c|c|c|c|c|c|c|c|c|}
\hline & \multicolumn{8}{|c|}{ Contact person's community role } & & & \multirow[b]{3}{*}{$\chi^{2}(3)$} \\
\hline & \multicolumn{2}{|c|}{$\begin{array}{l}\text { Community } \\
\text { and public } \\
\text { officials }\end{array}$} & \multicolumn{2}{|c|}{$\begin{array}{c}\text { Mental } \\
\text { health } \\
\text { professionals }\end{array}$} & \multicolumn{2}{|c|}{$\begin{array}{l}\text { General } \\
\text { public }\end{array}$} & \multicolumn{2}{|c|}{ Clergy } & \multicolumn{2}{|c|}{ Totals } & \\
\hline & $n$ & $\%$ & $n$ & $\%$ & $n$ & $\%$ & $n$ & $\%$ & $n$ & $\%$ & \\
\hline \multicolumn{12}{|c|}{ Did the contact involve gaining access to a forum to publicize GROW? } \\
\hline Yes & 102 & 46 & $73^{\circ}$ & 52 & 105 & 79 & 27 & 63 & 307 & 57 & $39.4^{a}$ \\
\hline No & 120 & 54 & 68 & 48 & 28 & 21 & 16 & 37 & 232 & 43 & \\
\hline \multicolumn{12}{|c|}{ Did the contact involve gaining access to potential GROW members? } \\
\hline Yes & 44 & 20 & $44^{\circ}$ & 31 & 44 & 33 & 20 & 47 & 152 & 28 & $17.0^{a}$ \\
\hline No & 178 & 80 & 97 & 69 & 89 & 67 & 23 & 53 & 387 & 72 & \\
\hline \multicolumn{12}{|c|}{ Did the contact involve securing a meeting site? } \\
\hline Yes & 36 & 16 & 8 & 6 & 2 & 2 & 14 & 33 & 60 & 11 & $42.5^{a}$ \\
\hline No & 186 & 84 & 133 & 94 & 131 & 98 & 29 & 67 & 479 & 89 & \\
\hline \multicolumn{12}{|c|}{ Did the contact involve securing financial support? } \\
\hline Yes & 25 & 11 & 0 & 0 & 7 & 5 & 0 & 0 & 32 & 6 & $23.0^{a}$ \\
\hline No & 197 & 89 & 141 & 100 & 126 & 95 & 43 & 100 & 507 & 94 & \\
\hline Totals & 222 & 41 & 141 & 26 & 133 & 25 & 43 & 8 & 539 & & \\
\hline
\end{tabular}

${ }^{a} p<.001$.

munity/public officials, and (d) community and public officials were the primary targets for obtaining financial support. These data also suggest that membership development was considered the most important resource for organizational growth.

Fieldworkers' flexible and responsive expansion activities are demonstrated by their pattern of contacts with potential resource providers in different geographical regions. Table III suggests that the Fieldworkers focused on different resources in the four geographical regions. Fieldworkers in the Chicago area were most often involved in efforts to secure meeting space, whereas those in Central Illinois were least involved in this activity. A larger percentage of the fund-raising contacts took place in Central Illinois. Public relations was most prevalent in Southern Illinois and least likely to occur in the Chicago area. Finally, there was a trend for less membership recruitment in the Northwestern region. These results suggest that GROW focused on different resources depending on the needs of a particular location. Instead of having a single-minded and rigid strategy for identifying and obtaining resources, GROW used a flexible approach that employed multiple tactics.

Investigative reporting and observation corroborate the results reported in Tables II and III. When Fieldworkers wanted to expand membership they contacted mental health professionals for referrals and held 
Table III. Resources Mobilized in Different Geographical Regions

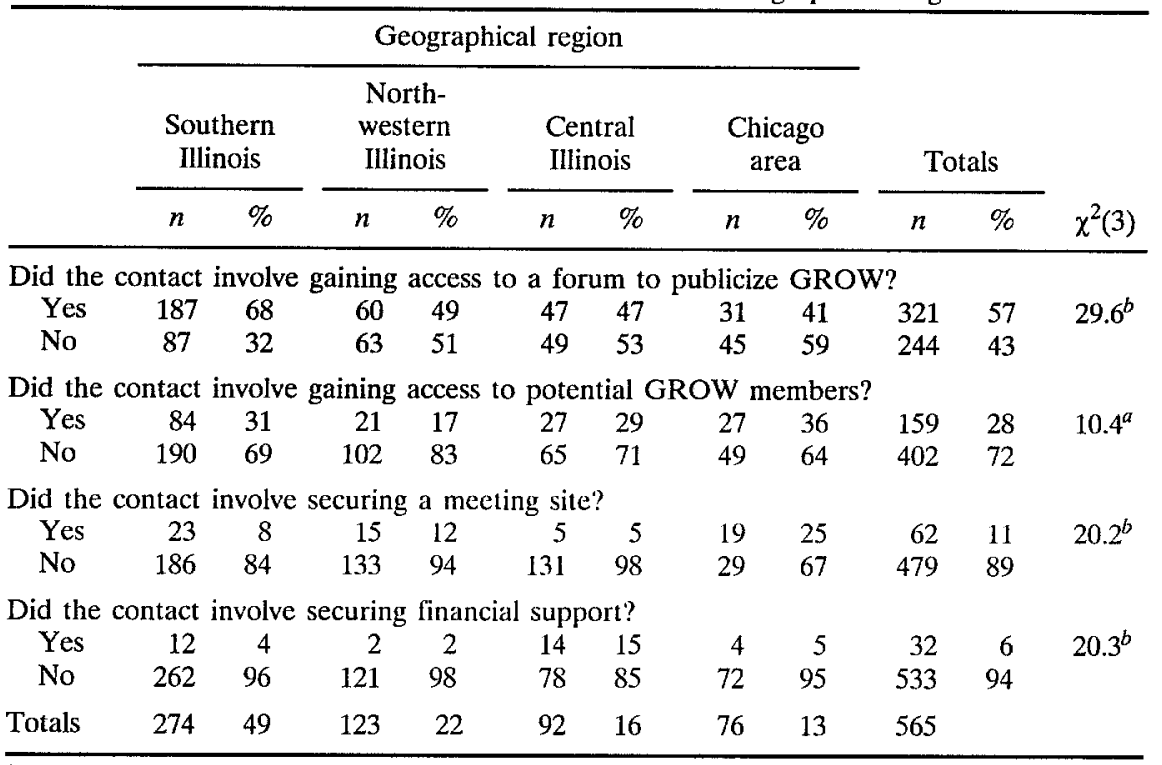

$a_{p}<.05$.

$b_{p}<.001$.

public meetings to tell the public about the organization. When Fieldworkers discussed plans to start a new group at staff meetings, clergy were typically suggested as potential providers of meeting space, but were rarely mentioned for other resources such as money.

The regional differences identified by the Fieldworkers' logs were also observed by our investigative reporting techniques. GROW's strongest efforts to secure financial support were made in Central Illinois where the least amount of State assistance was offered. Efforts made by both the Fieldworkers and the Program Coordinator included contacting private donors such as local business leaders, the United Way, and the County Mental Health Boards. Fieldworkers in larger metropolitan areas spoke more about problems with meeting space availability than staff in rural areas, and intense public relations efforts were the prime concern of Fieldworkers in rural Southern Illinois.

Flexibility in Public Presentations. Over half of the Fieldworkers' contacts involved gaining access to a public forum. Our observations of presentations noted GROW's flexibility and the diversity of themes in GROW's public presentations. At a community education workshop entitled, "Christianity and Mental Health," the audience was primarily clergy and churchaffiliated social service workers. Spirituality was a recurrent theme of this 
workshop with an emphasis on the link between personal adjustment and beliefs in a divine being.

At another presentation to the staff of a State psychiatric facility, the Program Coordinator emphasized the helping components of mutual help and the number of service hours provided in mutual help contexts. When a participant asked about GROW's reference to God in the group meetings, the Program Coordinator deemphasized the importance of spirituality. He said God was an optional part of the GROW program and an individual choice. He stressed that GROW's interpretation of spirituality was mutual respect and appreciation for fellow human beings more than it was a belief in God. Neither spirituality nor service hours were stressed at public meetings predominantly attended by community residents. In these public forums details about the organization goals, group process and the development of a sharing and caring social network were emphasized.

\section{Strategies for Mobilizing Internal Resources}

Fieldworkers mobilized internal resources to keep the groups viable and operating according to GROW's goals and procedures. Mobilizing internal resources most often meant recruiting members and developing local leadership. As the organization expanded with unexpected speed, however, the organization's leaders needed to attend to staff development issues as well.

Recruiting Group Members and Leaders. The Fieldworkers recruited members through their contacts at churches, social service programs, and public events. To encourage members to attend meetings, Fieldworkers often picked up members at their homes and drove them to the meetings. At the meetings, the Fieldworkers modeled appropriate leadership skills, encouraged other members to take on leadership roles, and taught members the essential components of GROW meetings.

Once a group was started, Fieldworkers focused their efforts on identifying potential leaders and encouraging them to assume a leadership role. Fieldworkers identified new members with leadership abilities or interests and nurtured a relationship with these persons before encouraging them to assume leadership positions. Between group meetings, Fieldworkers met informally with members in order to be supportive and to express confidence in the members' abilities. The members often accepted group leadership positions because of their growing confidence and the Fieldworkers' support. Maintaining good relationships with members was the Fieldworkers' primary means for supporting group organizers and ensuring that the groups followed GROW's group procedures. GROW also held semiannual training sessions for Organizers, Recorders, and Leaders. These 
sessions provided opportunities to discuss issues, solve problems, and learn skills for taking on new leadership roles.

Staff Development. The rapid expansion toward the end of this study also forced GROW to consider new methods for recruiting and training Fieldworkers. GROW's organizational leaders typically identified potential Fieldworkers among the group organizers. They then trained Fieldworkers through an apprentice system with other Fieldworkers. The rate of growth, however, did not allow for the time required for GROW staff to train indigenous leaders to become Fieldworkers. The Fieldworker staff grew from 3 in April 1983 to 13 by April 1985. In 1983, all the Fieldworkers had risen from the Illinois membership, but of the 10 new Fieldworkers hired, 5 were brought in from the Australia and New Zealand GROW organizations and one was a social worker hired from the community. Only four of the new Fieldworkers came up from the local ranks of group organizers.

The rapid expansion also resulted in the development of new organizational roles and further role delineation. In geographical areas where three to five Fieldworkers operated, one Fieldworker was identified as that region's Program Coordinator. This Regional Coordinator was responsible for coordinating and hiring Fieldworkers and raising money for the region. A story about GROW in the Reader's Digest generated so many inquiries that a new organizational role was created. An individual was hired to respond to the requests and edit a newsletter to keep interested parties informed about GROW's activities and needs.

\section{DISCUSSION}

This study illustrates how one mutual help organization successfully developed from a localized group to a statewide organization. Our confidence in the study's findings is strengthened by the consistency of the results across multiple methods and sources of information. Three central themes emerged from the data that describe GROW's successful expansion strategies: (a) identifying multiple resource providers; (b) developing flexible resource mobilization strategies; and (c) creating underpopulated settings.

GROW approached different providers for mobilizing particular resources depending on the setting and circumstances. Staff targeted clergy and public officials for space needs, focused on personnel issues in rural areas, and worked on fund-raising in regions providing the least financial support. A varied approach for obtaining needed resources may have exposed GROW to a variety of audiences, avoided repeated competition with rival organizations, and avoided overtaxing any one resource provider. This 
strategy also permitted GROW to address issues relevant to particular geographical areas and to take advantage of unique opportunities to start new groups.

The flexible nature of GROW's resource mobilization strategy was found in several instances. GROW targeted particular populations and familiarized them with the organizational characteristics that best matched each group's orientation. This was evidenced by the varying content of their presentations to clergy, social service workers, or lay people. For example, GROW's Program Coordinator presented GROW's spiritual emphasis when he spoke to clergy, but stressed the number of service hours provided by GROW when he spoke to administrative personnel and mental health professionals. This tactic helped GROW fit into different service environments and value systems.

The manner in which personnel development was addressed during periods of rapid growth is another example of GROW's flexibility. GROW managed to cope with the organizational crisis of serious underpopulation by delineating specific organizational roles for mobilizing particular resources. This was indicated by their development of new roles to respond to organizational change, utilization of professional group Sponsors to fill a leadership void, and importation of Fieldworkers from outside Illinois. In spite of GROW's flexibility in its expansion strategies, it strives to ensure that the structure and process of the group meetings follow the fixed GROW group method.

GROW started new groups primarily by creating underpopulated settings and then identifying the membership to fill the roles needed to maintain a mutual help group. This approach required actively reaching out to professionals and lay people for recruiting members and developing community support in new territories. Groups were often started in communities where only minimal interest was expressed. In some cases, GROW's leadership started groups, even before they had the necessary membership, with the belief that they could cultivate enough interest to sustain the group. Like Johnny Appleseed, GROW planted new groups without a great deal of consideration as to whether or not the environment was right for them to survive. The creation of underpopulated settings by the Johnny Appleseed approach may have been a critical facet of GROW's successful expansion. This tactic enabled GROW to extend its accessibility to many people across a wide geographical area and expand into communities that would not necessarily have learned about GROW.

Underpopulated groups may also compel members to make a commitment to the organization at the earliest stages of their involvement. Members are promptly asked to fill meaningful organizational roles which can have the dual effect of supporting the organization and helping in- 
dividuals learn skills to become healthy contributors to community living. Underpopulated settings may provide meaningful opportunities for members to take responsibility, develop independence, and share in the struggle for self-improvement.

Opportunities to provide and receive help may be one reason why the creation of underpopulated settings is a successful expansion strategy. Members may have maintained involvement in GROW because they felt satisfied and inspired by helping others who needed support and by obtaining support themselves when they needed it. Bidirectional support (i.e., providing and receiving support) has been found to be related to positive ratings of group benefits and satisfaction by members in both religious settings (Maton, 1987) and self-help groups (Maton, 1988). In a study of actual group behavior displayed by GROW members, Roberts (1989) found that those who provided more help to others during the meeting were more likely to attend meetings regularly. This process of sharing leadership may empower lay people to become less dependent on professional help and more involved in helping themselves and each other (Rappaport, Reischl, \& Zimmerman, in press). Through involvement in GROW's expansion, members may also experience the empowering feeling that they are involved with a successful organization.

GROW's expansion efforts may have been successful because they encouraged collaboration and cooperation among potential competitors. They seem to have carved out a niche that does not interfere with the mental health system or threaten the role of professionals. This is especially evidenced by the involvement of professionals as Sponsors of groups until membership developed leadership skills. GROW focused on the positive aspects of the organization, emphasizing how it complements existing services. Their literature even calls GROW "the missing link" in mental health care and suggests a team approach with professionals and family. GROW's staff worked hard to build bridges and make alliances rather than defend positions and fight battles.

GROW's expansion strategies may have some negative consequences as well. The emphasis (or deemphasis) of different aspects of their program for different populations may be interpreted as inconsistency in the organization and eventually erode their credibility with professionals and the public. Starting groups before the necessary leadership is available to operate them properly may strain existing leaders as they begin to take on too much responsibility. These members may become frustrated and leave the organization. The absence of specific guidelines for starting a new group may also make it difficult for new Fieldworkers (especially those hired from outside of the organization) to be effective organizational agents. The involvement of professionals may also unwittingly influence the 
character of groups and the behavior of individual members. Toro et al. (1988) found that the social climate in groups led by mental health workers differed from those led by indigenous leaders. Nevertheless, GROW appears to have managed these issues well, as evidenced by their continued development over time.

Descriptive studies such as this have some limitations. One limitation is that the data may be vulnerable to alternative causal explanations. For example, one could argue that external events, not GROW's actions, explain the rapid and successful growth. The State's deinstitutionalization mandate is one salient external event that could explain GROW's successful expansion. Several factors suggest, however, that it may be only a partial explanation. First, GROW did not passively wait for opportunities to start new groups, rather, they actively sought diverse sources of support and types of resources. Second, the mandate did not always result in the same type of resource opportunity nor did all regions offer support. The Southern region offered money and professional support, other regions offered only to refer patients, and still others did not provide any support. Third, involvement with the State was not easy or cost-free, nor did it guarantee successful expansion. GROW had to develop new strategies to cope with State support and struggle with the State to develop acceptable monitoring policies.

Several organizational theories suggest that characteristics of resources, not organizations, determine why and how resources are sought (Aldrich, 1979; Emery \& Trist, 1965; Yuchtman \& Seashore, 1967). Other issues such as leadership characteristics, environmental readiness, organizational goals, and policies that encourage community volunteerism may also provide alternative explanations of the data. Another limitation of this study is that the results may not be representative of other types of mutual help groups or other community-based voluntary organizations. Our goal, however, was to describe the process of organizational expansion and to raise questions for future research. Generalizability of the findings, and organizational and environmental characteristics that enhance or diminish growth are all valuable areas for future research.

This study contributes to the organizational development literature by providing an example of the expansion of a not-for-profit communitybased organization. Investigators have studied the process of organizational growth; however, most of the research focuses on business organizations (Cafferata, 1982; Van de Ven, Hudson, \& Schroeder, 1984), the process of starting new organizations (Bartunek \& Betters-Reed, 1987; Sarason, Zitnay, \& Grossman, 1971), or the issues associated with the survival of organizations (Kegan, 1981; Lindgren, 1987). Few studies provide in-depth description of the methods used by not-for-profit community organizations 
to extend their influence, increase their membership, and maintain their survival. Lindgren (1987) provided a notable exception in her analysis of a citizen advocacy group. Our findings parallel Lindgren's in that we both found shared leadership, delineation of specific roles for members, and diverse and collaborative community contacts contributed to the longevity and success of each organization.

Our study also suggests that integrating resource mobilization theory with Barker's behavior setting theory may provide a useful framework for studying the expansion of voluntary organizations. Resource mobilization theory provides a useful conceptual framework for understanding efforts to identify community support and obtain resources. In voluntary organizations, where members are a vital resource, strategies for facilitating participation may be crucial to the survival and expansion of the organization. Creation of underpopulated settings is one way of engaging new members and increasing their involvement in and commitment to the organization.

GROW's expansion strategy may serve as a blueprint for success for locally initiated and operated organizations because they have been able to maintain organizational integrity while also spreading their influence over a wide geographical area. The strategy may require the three-pronged approach of (a) identification of multiple resource providers, (b) flexibility in securing resources and defining organizational roles, and (c) creation of underpopulated settings. Alone, any of these strategies may not be effective, but together they may provide a way for grass-roots organizations to expand their influence and serve new communities. GROW, in effect, created its own success story by actively expanding into new areas, while creating meaningful roles to encourage members' involvement. These accomplishments are particularly noteworthy in that they were achieved by people, many of whom have a long history of being diagnosed as mentally ill and being hospitalized, without dependence on professionals. Their ability to create a successful organization stands as testimonial to the power of mutual help as a vehicle for people to obtain resources, create their own social niches, and develop a sense of empowerment.

\section{REFERENCES}

Aldrich, H. E. (1979). Organizations and environments. Englewood Cliffs, NJ: Prentice Hall. Barker, R. G. (1960). Ecology and motivation. Nebraska Symposium on Motivation, 8, 1-44.

Barker, R. G., \& Gump, P. V. (1964). Big school, small school: High school size and student behavior. Stanford, CA: Stanford University Press.

Bartunek, J. M., \& Betters-Reed, B. L. (1987). The stages of organizational creation. American Journal of Community Psychology, 15, 287-303.

Bailey, M. B. (1965). Al-Anon family groups as an aid to wives of alcoholics. Social Work, $10,68-74$. 
Barrett, C. J. (1978). Effectiveness of widow's groups in facilitating change. Journal of Consulting and Clinical Psychology, 46, 20-30.

Biegel, D. E., \& Yamatani, H. (1987). Help-giving in self-help groups. Hospital and Community Psychiatry, 38, 1195-1197.

Borkman, T. (1990). Self-help groups at the turning point: Emerging egalitarian alliances with the formal health care system? American Journal of Community Psychology, 18, 321-332.

Cafferata, G. L. (1982). The building of democratic organizations: An embryological metaphor. Administrative Science Quarterly, 27, 280-303.

Charmaz, K. (1983). The grounded theory method: An explication and interpretation. In R. M. Emerson (Ed.), Contemporary field research (pp. 109-126). Boston: Little Brown.

Emerson, R. M. (1983). (Ed.). Contemporary field research. Boston: Little Brown.

Emery, F. E., \& Trist, E. L. (1965). The causal texture of organizational environments. Human Relations, 18, 21-32.

Ferree, M. M., \& Miller, F. D. (1985). Mobilization and meaning: Toward an integration of social psychological and resource perspectives on social movements. Sociological Inquiry, $55,38-61$.

Galanter, M. (1988). Zealous self-help groups as adjuncts to psychiatric treatment: A study of Recovery, Inc. American Journal of Psychiairy, 145, 1248-1253.

Gartner, A., \& Riessman, F. (Eds.). (1984). The self-help revolution (Vol. 10, Community Psychology Series). New York: Human Sciences.

Glaser, B., \& Strauss, A. (1967). The discovery of grounded theory. Chicago: Aldine.

Hinrichsen, G. A., Revenson, T. A., \& Shinn, M. (1985). Does self-help help? An empirical investigation of scoliosis peer support groups. Joumal of Social Issues, 41, 65-87.

Jacobs, M. K., \& Goodman, G. (1989). Psychology and self-help groups: Predictions on partnership. American Psychologist, 44, 536-545.

Jenkins, J. C. (1983). Resource mobilization theory and the study of social movements. Annual Review of Sociology, 9, 527-553.

Kegan, D. (1981). Contradictions in the design and practice of an alternative organization: The case of Hampshire College. Joumal of Applied Behavioral Science, 17, 79-97.

Kelly, J. G. (1988). A guide to conducting prevention research in the community: First steps. Prevention in Human Services, 6, 1-174.

Kurtz, E. (1979). Not-God: A history of alcoholics anonymous. Center City, MN: Hazelden Educational Services.

Levine, M. (1980). Investigative reporting as a research method: An analysis of Bernstein's \& Woodward's All the President's Men. American Psychologist, 35, 626-638.

Levine, M. (1988). An analysis of mutual assistance. American Journal of Community Psychology, 16, 167-188.

Levy, L. H. (1979). Processes and activities in groups. In M. A. Lieberman, L. D. Borman, \& Associates (Eds.), Self-help groups for coping with crisis. San Francisco: Jossey Bass.

Lincoln, Y. S., \& Guba, E. G. (1986). But is that rigorous?: Trustworthiness and authenticity in naturalistic evaluation. In D. D. Williams (Ed.), Naturalistic evaluation: New directions for program evaluation (pp. 73-84). San Francisco: Jossey-Bass.

Lindgren, H. E. (1987). The informal-intermittent organization: A vehicle for successful citizen protest. Journal of Applied Behavioral Science, 23, 397-412.

Luke, D., Rappaport, J., \& Seidman, E. (1991). Setting phenotypes in a mutual help organization: Expanding behavior setting theory. American Joumal of Community Psychology. 19, 147-167.

Maton, K. I. (1987). Patterns and psychological correlates of material support within a religious setting: The bidirectional support hypothesis. American Joumal of Community Psychology, 15, 185-207.

Maton, K. I. (1988). Social support, organizational characteristics, psychological well-being, and group appraisal in three self-help group populations. American Joumal of Community Psychology, 16, 53-78.

Maton, K. I., Leventhal, G. S., Madara, E. S., and Julien, M. (1988). The birth and death of self-help groups: A population ecology perspective. In A. H. Bender \& E. I. Bender 
(Eds.), Helping one another: Self-help groups in a changing world. Oakland, CA: Third Party.

McCarthy, J. D., \& Zald, M. N. (1977). Resource mobilization and social movements: A partial theory. American Joumal of Sociology, 82, 1212-1241.

Perkins, D., Burns, T., Perry, J., \& Nielsen, K. (1988). Behavior setting theory and community psychology: An analysis and critique. Joumal of Community Psychology, 16, 355-371.

Raiff, N. R. (1984). Some health related outcomes of self-help participation: Recovery, Inc. as a case example of a self-help organization in mental health. In A. Gartner \& F. Riessman (Eds.), The self-help revolution. New York: Human Sciences.

Rappaport, J. (1990). Research methods and the empowerment social agenda. In P. Tolan, C. Keys, F. Chertok, \& L. Jason (Eds.), Researching community psychology (pp. 51-63). Washington, DC: American Psychological Association.

Rappaport, J., Reischl, T. M., \& Zimmerman, M. A. (in press). Mutual help mechanisms in the empowerment of former mental patients. In D. Saleebey (Ed.), The strengths perspective in social work practice: Power in the people. White Plains, NY: Longman.

Rappaport, J., Seidman, E., Toro, P. A., McFadden, L. S., Reischl, T. R., Roberts, L. J., Salem, D. A., Stein, C. H., \& Zimmerman, M. A. (1985). Finishing unfinished business: Collaborative research with a mutual help organization. Social Policy, 15 (Winter), 12-25.

Riessman, F. (1985). New dimensions in self-help. Social Policy, 15 (Winter), 2-4.

Roberts, L. J. (1989). Giving and receiving help: Group behavioral predictors of outcomes for members of a mutual help organization. Unpublished doctoral dissertation, University of Illinois, Champaign.

Salem, D. A., Seidman, E., \& Rappaport, J. (1988). Community treatment of the mentally ill: The promise of mutual help organizations. Social Work, 33, 403-408.

Sarason, S. B., Zitnay, G., \& Grossman, F. K. (1971). The creation of a community setting. Syracuse, NY: Syracuse University Press.

Spiegel, D., Bloom, J. R., \& Yalom, I. (1981). Group support for patients with metastatic cancer: A randomized prospective outcome study. Archives of General Psychiatry, 38, 527533.

Toro, P. A., Reischl, T. R., Zimmerman, M. A., Rappaport, J., Seidman, E., Luke, D. A., \& Roberts, L. J. (1988). Professionals in mutual help groups: Impact on social climate and members' behavior. Journal of Consulting and Clinical Psychology, 56, 631-632.

U.S. Department of Health and Human Services. (1988). The Surgeon General's workshop on self-help and public health (Publication No. 224-250-88). Washington, DC: U.S. Government Printing Office.

Van de Ven, A. H., Hudson, R., \& Schroeder, D. M. (1984). Designing new business startups: Entreprenurial, organizational, and ecological considerations. Journal of Management, 10, 87-107.

Van Maanen, J. (1983). (Ed.). Qualitative methodology. Beverly Hills, CA: Sage.

Wicker, A. W. (1987). Behavior settings reconsidered: Temporal stages, resources, internal dynamics, context. In D. Stokols \& A. Altman (Eds.), Handbook of environmental psychology. New York: Wiley.

Wicker, A. W. (1989). Substantive theorizing. American Joumal of Community Psychology, 17, 531-547.

Wollert, R. W. (1986). Psychosocial helping processes in a heterogeneous sample of self-help groups. Canadian Journal of Community Mental Health, 5, 63-72.

Wollert, R. W., Levy, L. H., \& Knight, B. G. (1982). Help giving in behavioral control and stress coping self-help groups. Small Group Behavior, 13, 204-218.

Yuchtman, E., \& Seashore, S. (1967). A system resource approach to organizational effectiveness. American Sociological Review, 32, 891-903.

Zimmerman, M. A., McFadden, L. S., Toro, P. A., Salem, D. S., Reischl, T. M., Rappaport, J., \& Seidman, E. (1985, May). Expansion of a mutual help organization: The "Johnny Appleseed" approach. Paper presented at the Midwest Psychological Association, Chicago, IL. 